Check for updates

Cite this: RSC Adv., 2018, 8, 22974

\title{
Bent-core dimers with top-to-bottom linkage between central units $\dagger$
}

\author{
Martin Horčic, ${ }^{a}$ Jiři Svoboda, (DD *a Vladimíra Novotná, (DD ${ }^{\mathrm{b}}$ Damian Pociecha (D) ${ }^{\mathrm{c}}$ \\ and Ewa Gorecka (iD c
}

A structurally new type of core-to-core dimer with a top-to-bottom linkage between the central cores of bent molecules is presented. The structure of the bent-core molecules was modified by changing the length of the spacer between the central cores and terminal chains, by changing the type of linkage groups in the bent-core arms and by variation of the terminal chain polarity - introducing polyfluoroalkyl and oligosiloxane units. Additionally, the outer phenyl ring was substituted with three alkyl chains to mimic a polycatenar system. For all compounds the mesophase behaviour and structural parameters were established to gain information about the molecular structure-mesomorphic property relationship.

Received 14th May 2018

Accepted 18th June 2018

DOI: $10.1039 / \mathrm{c} 8 \mathrm{ra0} 4108 \mathrm{c}$

rsc.li/rsc-advances molecular structure of dimers constituting mesogenic units are joined in various modes, the most frequently end-toend, ${ }^{6-9,12-16,27}$ and scarcely side-to-end ${ }^{11}$ and top-to-top. ${ }^{10}$ The mesomorphic properties of the end-to-end joined dimers are sensitive to the character of the spacer: materials with an alkylene spacer exhibited nematic and smectic phases ${ }^{9-12}$ and columnar phases ${ }^{13,14}$ depending on the length of the spacer, respectively. When the bent-core monomers were linked by an oligosiloxane and carbosilane unit, ferroelectric and antiferroelectric SmCP phases were observed for various number of siloxane units. ${ }^{6,89}$ The same effect was proved at nonsymmetrical dimers composed of a bent-core and rod-like units. $^{15,17-21,24}$ Few examples of columnar ${ }^{19-21}$ and SmCP pha$\operatorname{ses}^{22}$ typical for bent-shaped molecules were also found.

In our preliminary report ${ }^{28}$ we have presented a new type of bent-core liquid crystalline dimers designed by a top-to-bottom connection of bent-core central units by a propylenedioxy linking unit. The studied compounds showed a strong dependence of mesomorphic properties on the length of the terminal alkyl chains. While the compounds with short chains (ethyl, butyl) exhibited the SmA phases, lengthening the arms to hexyl and octyl resulted in appearance of the columnar $\mathrm{B}_{1}\left(\mathrm{Col}_{\mathrm{r}}\right)$ phase, and further lengthening to the decyl and dodecyl chain resulted in formation of the polar $\mathrm{SmC}_{\mathrm{A}} \mathrm{P}_{\mathrm{A}}$ phases. In this contribution we present synthesis and systematic physical studies of this new type of top-to-bottom bent-core dimers with respect to the length of the alkylene spacer, type, length and number of the terminal chains, and type and orientation of linking groups.

\section{Experimental}

\section{Synthesis of the studied compounds}

General chemical formula of the studied compounds Dm-n is shown in Fig. 1. We have varied the length of the spacer $(m)$, the 
<smiles>[Y]c1cc([Z2])cc([Z2])c1</smiles>

Fig. 1 General chemical formula of the studied top-to-bottom dimers Dm-n.

length and character of terminal chains $\left(\mathrm{R}^{1}, \mathrm{R}^{2}, \mathrm{R}^{3}\right.$ and $\left.\mathrm{R}^{4}\right)$ and linkage groups in outer part of arms, $\mathrm{Z}_{1}$ and $\mathrm{Z}_{2}$. Additionally, in some materials instead of terminal alkyls we utilized polyfluorinated or siloxanylalkyl chains (will be specified later). As a linking groups $\left(\mathrm{Z}_{1}, \mathrm{Z}_{2}\right)$ in the outer part of the bent-core molecules either ester groups with various orientation, photosensitive azo units were used, or two phenyl rings were joined directly (see Fig. 1). In the last series, the terminal benzene rings were substituted with multiple terminal chains (Y).
The detailed synthesis of the studied materials and characterisation of all compounds, i.e., synthesis of cores, intermediates and target compounds of all series Dm-n is summarised in the ESI. $\dagger$

\section{Experimental methods}

Differential scanning calorimetry (DSC) measurements were performed using Perkin-Elmer 7 calorimeter. The compounds 2-5 $\mathrm{mg}$ were hermetically sealed in aluminium pans and

Table 1 Mesomorphic properties of dimers D4- $\mathrm{n}$ with the butylenedioxy spacer ${ }^{a}$

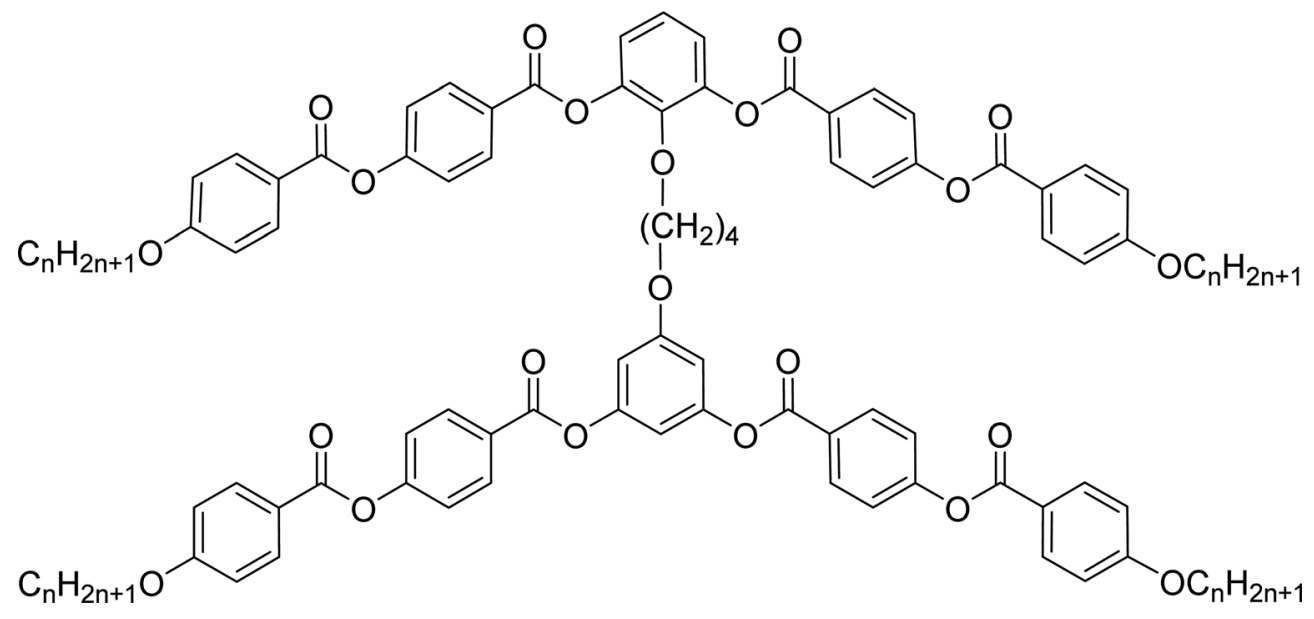

\begin{tabular}{|c|c|c|c|c|c|c|}
\hline Comp. & $n$ & $\mathrm{mp}[\Delta H]$ & $T_{\mathrm{cr}}[\Delta H]$ & $\mathrm{M}_{1}$ & $T_{\operatorname{tr}}[\Delta H]$ & Iso \\
\hline D4-2 & 2 & $203[+53.6]$ & $140[-49.9]$ & SmA & $207[-28.5]$ & - \\
\hline D4-4 & 4 & $163[+40.9]$ & $156[-40.3]$ & SmA & $186[-27.8]$ & - \\
\hline D4-8 & 8 & $154[+68.3]$ & $101[-31.1]$ & $\mathrm{B}_{1}$ & $136[-19.8]$ & - \\
\hline D4-10 & 10 & $122[+49.4]$ & $52[-18.5]$ & $\mathrm{SmC}_{\mathrm{A}} \mathrm{P}_{\mathrm{A}}$ & $125[-36.4]$ & • \\
\hline D4-12 & 12 & $102[+36.8]$ & $49[-25.5]$ & $\mathrm{SmC}_{\mathrm{A}} \mathrm{P}_{\mathrm{A}}$ & $134[-40.4]$ & • \\
\hline
\end{tabular}

${ }^{a}$ Melting point, mp, phase transition temperatures, $T_{\mathrm{tr}}$, and temperature of crystallization, $T_{\mathrm{cr}}$, in ${ }^{\circ} \mathrm{C}$, and corresponding enthalpy changes, $\Delta H$, are in brackets in $\mathrm{kJ} \mathrm{mol}^{-1}$. 


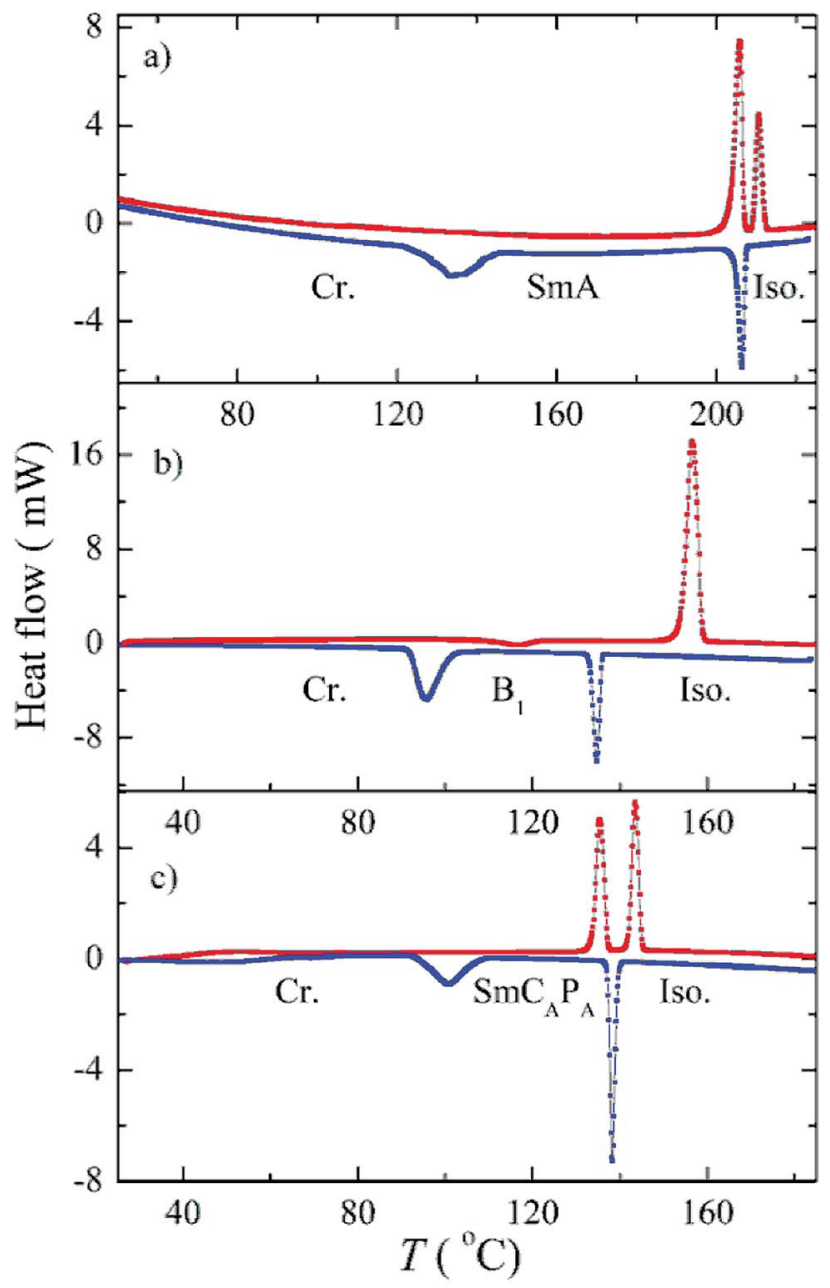

Fig. 2 DSC plots taken at the second heating (red) and the subsequent second cooling run (blue colour) for selected compounds: (a) D4-2, (b) D4-8, and (c) D4-12. Phases are designated in the corresponding temperature interval.

inserted into the calorimeter chamber, which was filled during measurements with nitrogen atmosphere. Temperature and enthalpy change values were calibrated on extrapolated onsets for melting points of water, indium and zinc. Mostly the calorimetric measurements were performed on heating and subsequent cooling runs at a rate of $5 \mathrm{~K} \mathrm{~min}^{-1}$.

The phases were identified from textures observed under a polarizing optical microscope Nikon Eclipse E600Pol. The glass cells for texture observation and electro-optical studies were prepared from glasses with ITO transparent electrodes (5 $\times 5 \mathrm{~mm}^{2}$ ) separated by two mylar sheets defining the cell thickness (usually of about $3 \mu \mathrm{m}$ ). The glass cells were filled with studied compounds in the isotropic (Iso) phase by capillary action. The Linkam LTS E350 heating/cooling stage was used, which enabled temperature stabilization within $\pm 0.1 \mathrm{~K}$.

The electro-optical properties have been studied using a driving voltage from generator Philips PM 5191, which was accompanied by an amplifier. The voltage of maximum amplitude $\pm 200 \mathrm{~V}$ was provided for the measuring system and the digital oscilloscope Tektronix DPO4034 display the switching current $v s$. time. The dielectric spectroscopy was measured using a Schlumberger 1260 impedance analyser in the frequency range of $10 \mathrm{~Hz}$ to $10 \mathrm{MHz}$, at stabilized temperatures during frequency sweeps.

The X-ray diffraction studies were performed using Bruker Nanostar system with $\mathrm{CuK} \alpha$ radiation (wavelength $\lambda=1.5418$ $\AA)$, Vantec 2000 area detector, MRI TCPU H heating stage working in the transmission mode and Bruker GADDS system (CuK $\alpha$ radiation, Vantec 2000 area detector) working in reflection mode. In both systems the temperature stability was $0.1 \mathrm{~K}$. Partially oriented samples for experiments in reflection were prepared as droplets on heated surface.

\section{Mesomorphic properties}

\section{The role of the terminal alkyl chains length}

In the previous manuscript we have reported a study of top-tobottom dimers with the propylenedioxy spacer designated as D3-n. ${ }^{28}$ We demonstrated that the increasing length of the terminal chains $\left(\mathrm{R}=\mathrm{C}_{n} \mathrm{H}_{2 n+1}\right)$ resulted in variety of the mesophases formed, starting from the intercalated SmA for the shortest homologue through the columnar $\mathrm{B}_{1}$ phase to the lamellar SmCP phases for the longest homologues. Herein we have prepared and studied homologues D4-n (the structure of materials is shown in the heading of Table 1) with the butylenedioxy spacer. We have modified the terminal chains length $\mathrm{R}$

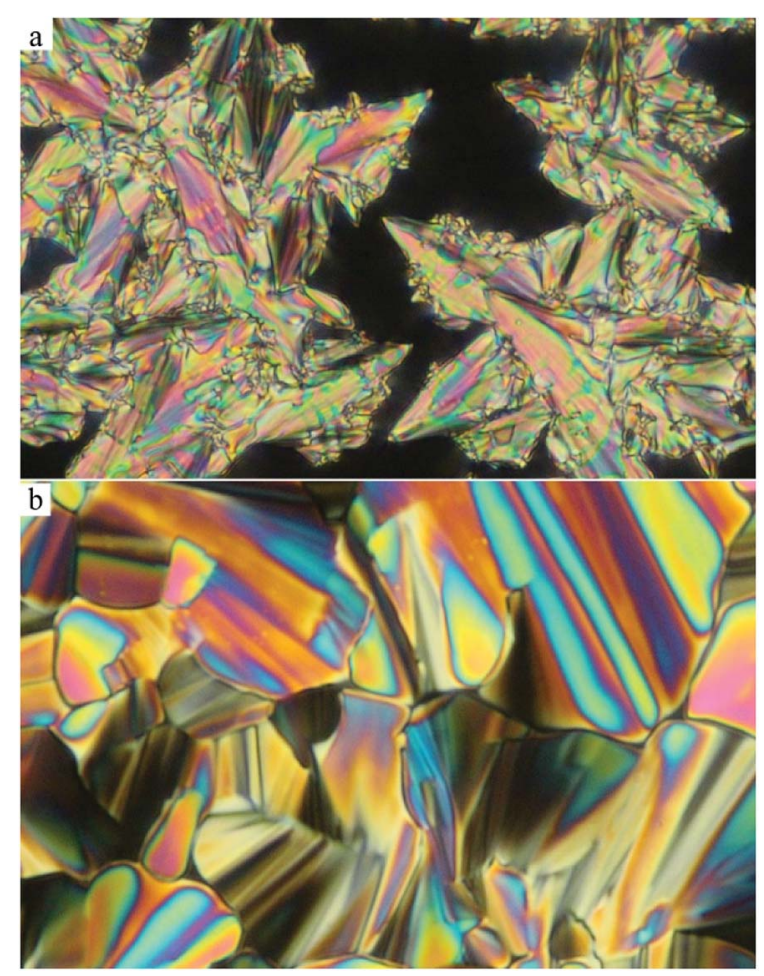

Fig. 3 (a) Planar texture of D4-6 at the isotropic-SmA phase transition at the temperature $T=159{ }^{\circ} \mathrm{C}$; (b) planar texture of D4-8 in the $\mathrm{B}_{1}$ phase transition at the temperature $T=130{ }^{\circ} \mathrm{C}$. The width of the images is $200 \mu \mathrm{m}$. 


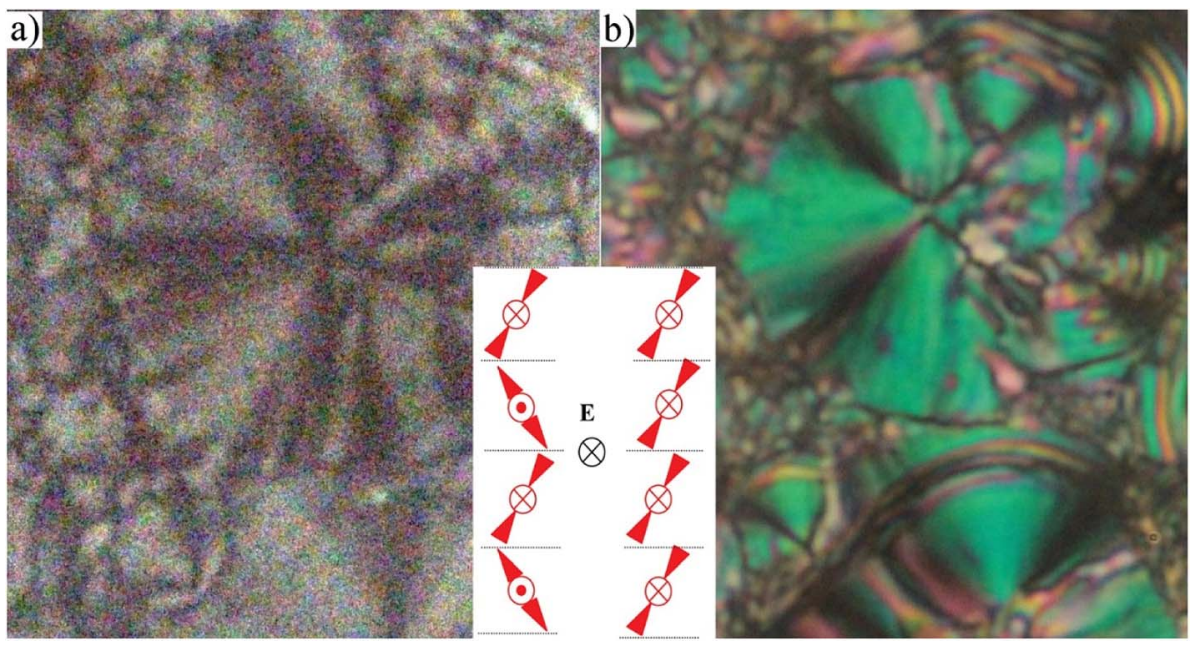

Fig. 4 The planar texture for D4-10 at $T=100^{\circ} \mathrm{C}$ : (a) after application of the electric field (in increased contrast), and (b) in the electric field $20 \mathrm{~V}$ $\mu \mathrm{m}^{-1}$. The width of the photo corresponds to about $100 \mu \mathrm{m}$. In the inset the schematic organization of bent-core molecules is shown in a homochiral domain without electric field (left column) and under the applied electric field $E$ (right column), when the average extinction turns for about 45 degrees.

from $\mathrm{C}_{2} \mathrm{H}_{5}$ to $\mathrm{C}_{12} \mathrm{H}_{25}$. The aim is to compare their behaviour with the previous results ${ }^{28}$ and obtain more information about molecular structure-mesomorphic properties relationship.
The phase sequence, the transition temperatures and corresponding enthalpy changes for this series are summarized in Table 1. DSC plots for selected homologues are presented in
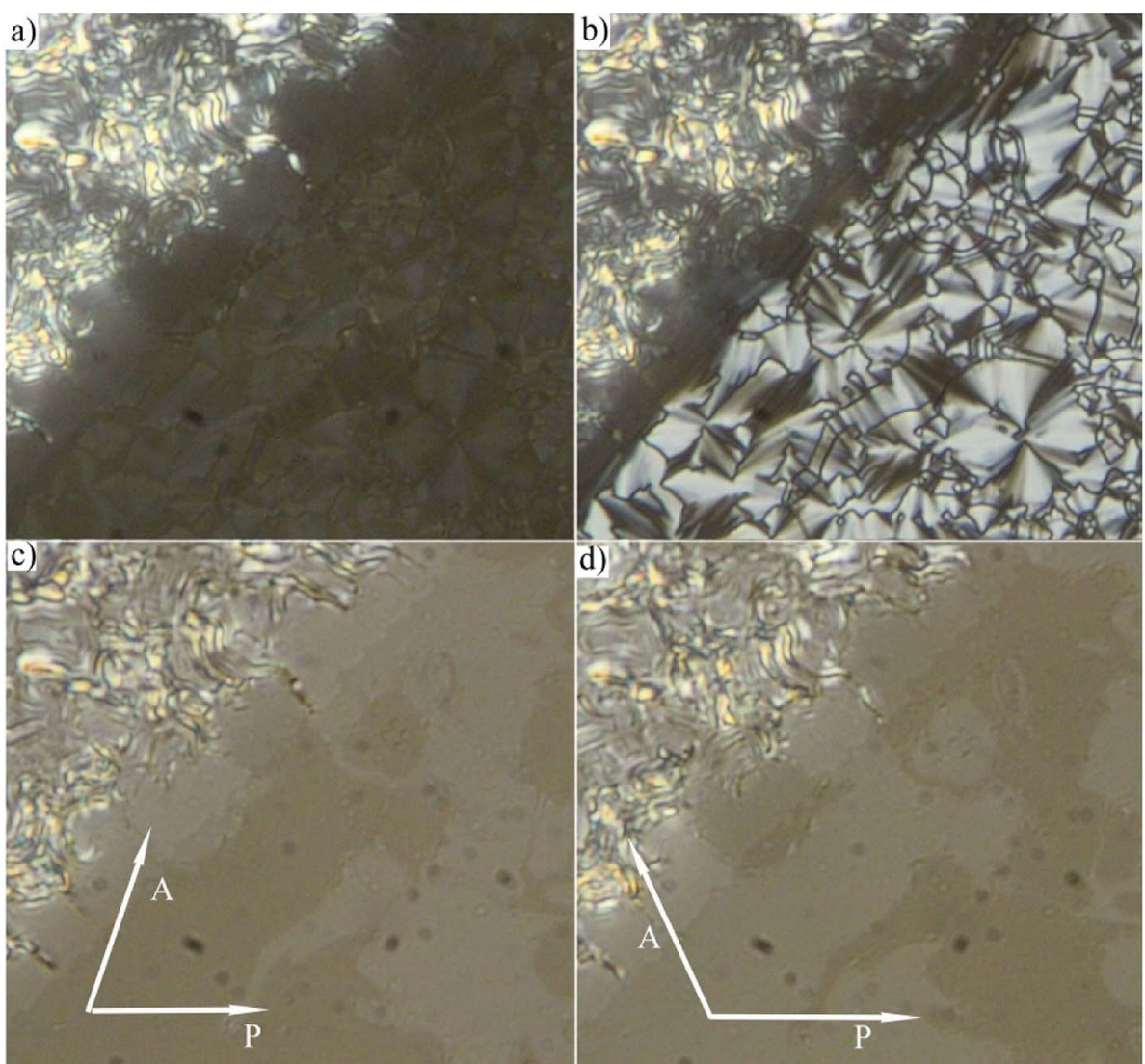

Fig. 5 Planar texture of D4-12 in the SmCP phase at $T=130^{\circ} \mathrm{C}$ : (a) the texture when the field was switched off and upper left part of the photo

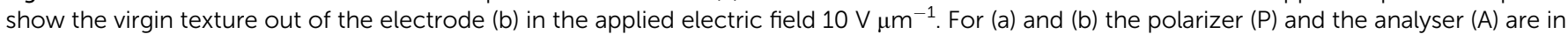
crossed position; (c) and (d) show the same texture as in (a) when rotation the analyser clockwise and anticlockwise. The width of every figure corresponds to $150 \mu \mathrm{m}$. 


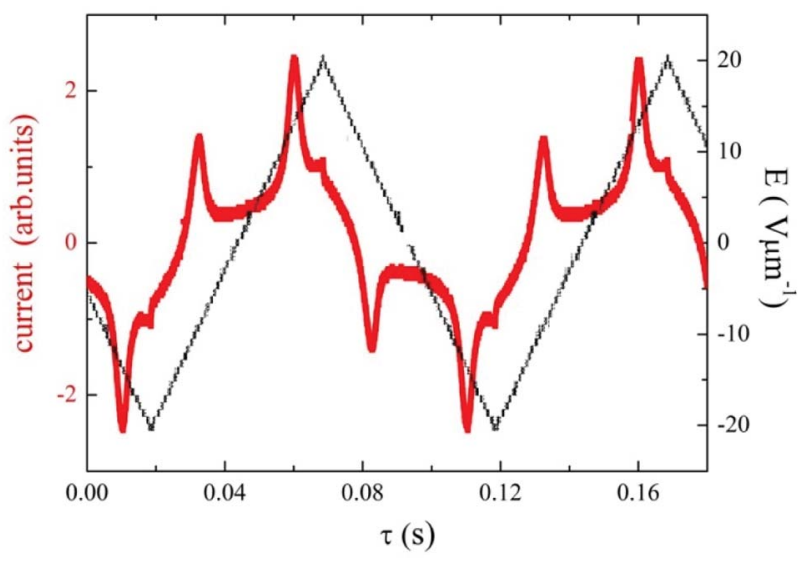

Fig. 6 For D4-12, the switching current versus time, $\tau$, for applied triangular voltage with intensity, $E$, at a frequency of $10 \mathrm{~Hz}$, taken in the $\mathrm{SmC}_{\mathrm{A}} \mathrm{P}_{\mathrm{A}}$ at $T=120^{\circ} \mathrm{C}$.

Fig. 2. Compounds D4-2 to D4-6 with the shortest alkyl chains exhibited the SmA phase. Fan-shaped texture has been found under polarizing microscope and no electro-optical response to the applied electric field has been detected. We consider the observed mesophase is a non-polar SmA phase, on contrary to polar SmAP phases described in literature. ${ }^{29}$ Due to the strong intercalation any switching in the electric field is blocked. For D4-6 the grow of the nuclei of the SmA phase at the Iso-SmA phase transition is presented in Fig. 3a. The developed planar texture in the SmA phase is demonstrated for D4-2 in ESI, Fig. S1. $\dagger$ The homologue D4-8 showed a columnar phase and typical textures with coloured domains were observed under polarizing microscope (Fig. 3b). Also for the columnar phase no electro-optical response was detected.

To confirm the LC phase identification based on textural observations, X-ray measurements were performed. X-ray pattern recorded in the SmA phase, with the sharp commensurate peaks at small-angle region and broad diffuse maximum at wide range of scattering angle, is typical for a lamellar phase with liquid-like positional order within the layers. Comparison between the measured layer spacing value, $d=16.7 \AA$ for D4-2, and estimated molecular length $L=33.6 \AA$ evidences a strongly intercalated character of the observed SmA mesophase. Analogously we have also proved the intercalated structure of SmA phases for longer homologues, D4-4 and D4-6. The broad diffuse maximum in the X-ray pattern corresponds to average in-plane distance of molecules about $4.5 \AA$.

In the X-ray pattern of the columnar phase formed by $\mathbf{D 4 - 8}$, there are few incommensurate signals in the small-angle region and diffuse maximum at wide scattering angle. The pattern could be indexed assuming centred orthorhombic crystallographic unit cell, that identifies $\mathrm{B}_{1}$-type columnar mesophase, which structure is built from smectic-layer fragments. ${ }^{5}$ The unit cell dimensions were established and we found that parameter $c$ is comparable to the molecular length (see Table S1 in ESI $\dagger$ ). The cell parameters for D4-8 are very similar to values presented for the propylenedioxy compounds D3-6 and D3-8. ${ }^{28}$ Thus, we can claim that the packing scheme of broken-layer fragments in the $\mathrm{B}_{1}$ phase presented for dimers D3-n in our preliminary paper is valid also for the analogues D4-n studied here.

For compounds D4-10 and D4-12 we have observed another type of the mesophase. D4-10 and D4-12 showed an electrooptical response and other features characteristic for SmCP phases. Virgin planar textures show very tiny features, however under the applied electric field a fan-shaped texture with circular domains appeared (Fig. 4) After switching off the electric field, the fan-shape texture turned to dark state with the extinction positions corresponding to the polarizers direction (Fig. 4a). The birefringence is very low and the contrast should be increased to recognize the fans. Under the applied electric field the extinction positions rotate by angle about 45 degrees and the birefringence increases with voltage (Fig. 4b). Fig. 5 shows the texture behaviour for homologue D4-12 after application of the applied electric field (Fig. 5a) and under the field (Fig. 5b); the left upper corner of each panel shows the virgin texture in area, which is not covered by the electrode. By rotating the polarizer from crossed position by an angle of about 7 degrees clockwise and anticlockwise, one can easily distinguish large domains (Fig. 5c and d), which corresponds homochiral state. We can conclude that the textures and
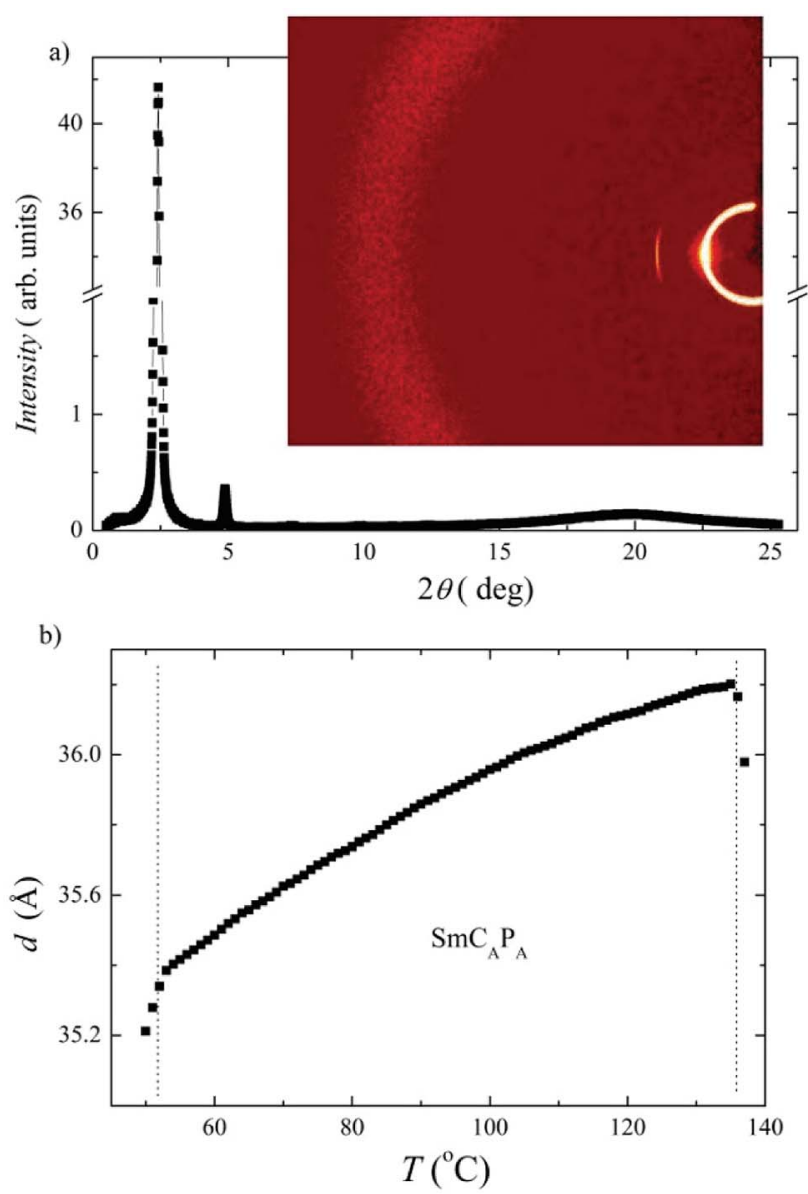

Fig. 7 X-ray measurements for compound D4-12: (a) the intensity versus the scattering angle at $T=70{ }^{\circ} \mathrm{C}$ in the $\mathrm{SmC}_{\mathrm{A}} \mathrm{P}_{\mathrm{A}}$ phase. In the inset in right upper corner $2 \mathrm{D} X$-ray pattern is shown at the same temperature; (b) temperature dependence of the layer spacing, $d$, taken on cooling. 
Table 2 Mesomorphic properties of dimers Dm-12 taken from DSC measurements ${ }^{a}$

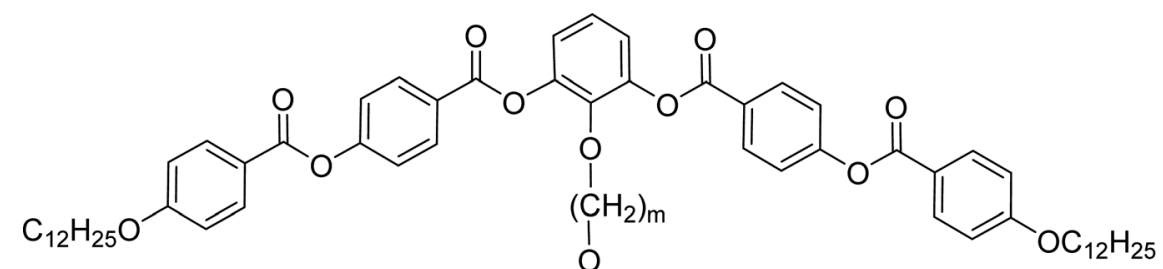

\begin{tabular}{|c|c|c|c|c|c|c|}
\hline Comp. & $m$ & $\mathrm{mp}[\Delta H]$ & $T_{\mathrm{cr}}[\Delta H]$ & $\mathrm{M}_{1}$ & $T_{\text {tr }}[\Delta H]$ & Iso \\
\hline D2-12 & 2 & $103[+40.6]$ & $85[-34.1]$ & $\mathrm{SmC}_{\mathrm{A}} \mathrm{P}_{\mathrm{A}}$ & $183[-45.4]$ & - \\
\hline D3-12 ${ }^{24}$ & 3 & $129[+37.3]$ & $99[-25.3]$ & $\mathrm{SmC}_{\mathrm{A}} \mathrm{P}_{\mathrm{A}}$ & $139[-39.4]$ & - \\
\hline D4-12 & 4 & $102[+36.8]$ & $49[-25.5]$ & $\mathrm{SmC}_{\mathrm{A}} \mathrm{P}_{\mathrm{A}}$ & $134[-40.4]$ & • \\
\hline D5-12 & 5 & $72[+28.8]$ & $*$ & $\mathrm{SmC}_{\mathrm{A}} \mathrm{P}_{\mathrm{A}}$ & $94[-41.0]$ & - \\
\hline D6-12 & 6 & $120[+98.1]$ & $106[-102.8]$ & - & - & - \\
\hline D8-12 & 8 & $118[+136.2]$ & $107[-90.9]$ & - & - & - \\
\hline D12-12 & 12 & $108[+104.3]$ & $91[-123.2]$ & - & - & • \\
\hline
\end{tabular}

${ }^{a}$ Melting point, mp, phase transition temperatures, $T_{\mathrm{tr}}$, and temperature of crystallization, $T_{\mathrm{cr}}$, in ${ }^{\circ} \mathrm{C}$, and corresponding enthalpy changes, $\Delta H$, in $\mathrm{kJ} \mathrm{mol}^{-1}$, taken on the second heating/cooling run are in brackets. Symbol ${ }^{*}$ shows that compound does not crystallise on cooling to $-20{ }^{\circ} \mathrm{C}$.<smiles>[R20]Oc1ccc(C(=O)Oc2ccc(OC(=O)c3ccc(OCCOc4c(OC(=O)c5ccc(OC(=O)c6ccc(OCCCCC)cc6)cc5)cc(OC)cc4OC(=O)c4ccc(OC(=O)c5ccc(OC(=O)c6ccc([R20])cc6)cc5)cc4)cc3)cc2)cc1</smiles>

\begin{tabular}{|c|c|c|c|c|c|c|c|c|c|}
\hline Comp. & $m$ & $\mathrm{R}^{1}$ & $\mathrm{R}^{2}$ & $\mathrm{R}^{3}$ & $\mathrm{mp}[\Delta H]$ & $T_{\mathrm{cr}}[\Delta H]$ & $\mathrm{M}_{1}$ & $T_{\mathrm{tr}}[\Delta H]$ & Iso \\
\hline D2-1212-FF & 2 & $\mathrm{C}_{12} \mathrm{H}_{25}$ & $\mathrm{C}_{12} \mathrm{H}_{25}$ & $\left(\mathrm{CH}_{2}\right)_{8} \mathrm{C}_{4} \mathrm{~F}_{9}$ & $90[+31.5]$ & $66[-19.6]$ & $\mathrm{SmC}_{\mathrm{A}} \mathrm{P}_{\mathrm{A}}$ & $202[-44.4]$ & - \\
\hline D3-1212-FF & 3 & $\mathrm{C}_{12} \mathrm{H}_{25}$ & $\mathrm{C}_{12} \mathrm{H}_{25}$ & $\left(\mathrm{CH}_{2}\right)_{8} \mathrm{C}_{4} \mathrm{~F}_{9}$ & $114[+44.7]$ & $70[-22.8]$ & $\mathrm{SmC}_{\mathrm{A}} \mathrm{P}_{\mathrm{A}}$ & $160[-38.3]$ & • \\
\hline D5-1212-FF & 5 & $\mathrm{C}_{12} \mathrm{H}_{25}$ & $\mathrm{C}_{12} \mathrm{H}_{25}$ & $\left(\mathrm{CH}_{2}\right)_{8} \mathrm{C}_{4} \mathrm{~F}_{9}$ & $123[+39.4]$ & $*$ & $\mathrm{SmC}_{\mathrm{A}} \mathrm{P}_{\mathrm{A}}$ & $120[-34.1]$ & - \\
\hline D3-FF-FF & 3 & $\left(\mathrm{CH}_{2}\right)_{8} \mathrm{C}_{4} \mathrm{~F}_{9}$ & $\left(\mathrm{CH}_{2}\right)_{8} \mathrm{C}_{4} \mathrm{~F}_{9}$ & $\left(\mathrm{CH}_{2}\right)_{8} \mathrm{C}_{4} \mathrm{~F}_{9}$ & $84[+28.7]$ & $*$ & $\mathrm{SmC}_{\mathrm{A}} \mathrm{P}_{\mathrm{A}}$ & $187[-42.5]$ & - \\
\hline D4-FF-FF & 4 & $\left(\mathrm{CH}_{2}\right)_{8} \mathrm{C}_{4} \mathrm{~F}_{9}$ & $\left(\mathrm{CH}_{2}\right)_{8} \mathrm{C}_{4} \mathrm{~F}_{9}$ & $\left(\mathrm{CH}_{2}\right)_{8} \mathrm{C}_{4} \mathrm{~F}_{9}$ & $86[+37.3]$ & $64[-28.7]$ & $\mathrm{SmC}_{\mathrm{A}} \mathrm{P}_{\mathrm{A}}$ & $180[-38.8]$ & - \\
\hline D3-SiF-SiF & 3 & $\left(\mathrm{CH}_{2}\right)_{11} \mathrm{SiMe}_{2} \mathrm{OSiMe}_{3}$ & $\left(\mathrm{CH}_{2}\right)_{8} \mathrm{C}_{4} \mathrm{~F}_{9}$ & $\left(\mathrm{CH}_{2}\right)_{11} \mathrm{SiMe}_{2} \mathrm{OSiMe}_{3}$ & $62[+29.2]$ & $71[-13.0]$ & $\mathrm{SmC}_{\mathrm{A}} \mathrm{P}_{\mathrm{A}}$ & $162[-40.3]$ & • \\
\hline
\end{tabular}

${ }^{a}$ Melting point, mp, phase transition temperatures, $T_{\text {tr }}$, and temperature of crystallization, $T_{\mathrm{cr}}$, in ${ }^{\circ} \mathrm{C}$, and corresponding enthalpy changes, $\Delta H$, in $\mathrm{kJ} \mathrm{mol}^{-1}$, are in brackets. Symbol ${ }^{*}$ shows that compound does not crystallise on cooling down to $-20{ }^{\circ} \mathrm{C}$. 


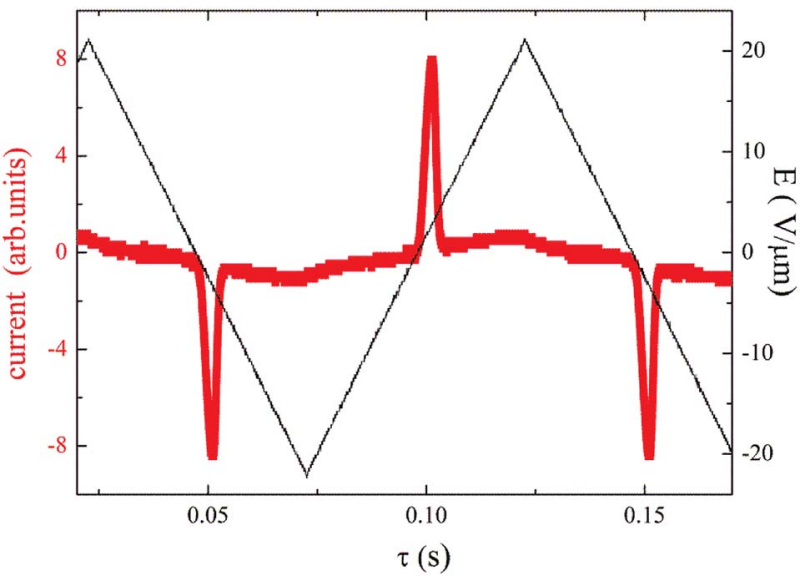

Fig. 8 For D3-SiF-SiF, the switching current versus time, $\tau$, for applied triangular voltage profile with maximum intensity $E=20 \mathrm{~V} \mathrm{\mu m}^{-1}$, taken in the $\mathrm{SmC}_{\mathrm{A}} \mathrm{P}_{\mathrm{A}}$ at $T=120^{\circ} \mathrm{C}$ and a frequency of $10 \mathrm{~Hz}$.

characteristic electro-optical behaviour allowed identification of the observed mesophases with the $\mathrm{SmC}_{\mathrm{A}} \mathrm{P}_{\mathrm{A}}$ phase.

Under applied electric field of a triangular profile, two peaks per half cycle have been detected, which confirms the antiferroelectric character of the observed SmCP mesophase. For D4-12 the switching current profile is shown in Fig. 6. The spontaneous electric polarization values, calculated by integration of the current profile, slightly increased on cooling for both D4-10 and D4-12 compounds, being in range 800-850 nC $\mathrm{cm}^{-2}$. Dielectric spectroscopy, performed in the frequency range $10 \mathrm{~Hz}$ to $1 \mathrm{MHz}$ revealed one distinct relaxation mode, which existed only within temperature interval of the $\mathrm{SmC}_{\mathrm{A}} \mathrm{P}_{\mathrm{A}}$ phase and disappeared in the isotropic and crystalline phases (Fig. S2 in ESI†).

X-ray diffraction measurements have been performed for D410 and D4-12 to confirm the lamellar character of the $\mathrm{SmC}_{\mathrm{A}} \mathrm{P}_{\mathrm{A}}$ phase. X-ray intensity profile shows several commensurate peaks in small angle region, from which the layer spacing, $d$, can be calculated. For compound D4-12 the intensity profile and temperature dependence of the layer spacing $d(T)$ are presented in Fig. 7a. The layer spacing decreases on cooling for both studied compounds, for D4-12 $d(T)$ is presented in Fig. 7b. Comparison of the calculated length of the D4-10 and D4-12 molecules on extended conformation with the measured $d$ values, suggest very high tilt angle value, $\sim 50$ degrees. Thus it is reasonable to assume that interdigitation of molecular terminal chains between neighbouring layers also takes place and contributes to lowering the effective smectic layer thickness.

The above described mesomorphic properties of the series D4-n compounds, having the butylenedioxy spacer are very similar to those observed for compounds D3-n with the propylenedioxy spacer. ${ }^{28}$ We have not observed typical odd/even effect of the spacer parity on the phase transition temperatures or mesomorphic behaviour for studied top-to-bottom dimers.

\section{The role of the length of the alkylenedioxy spacer}

Furthermore, we studied the role of the spacer length $(m$ number, see Fig. 1) and prepared a series of dimers Dm-12 with dodecyl terminal chains (Table 2) to support the polar packing. We have discovered that regardless the length and parity of atoms in the spacer, all prepared dimers D2-12 to D5-12 exhibited the SmCP phase, which was identified as the chiral $\mathrm{SmC}_{\mathrm{A}} \mathrm{P}_{\mathrm{A}}$ phase. Compound D3-12 was already reported ${ }^{28}$ and is included into Table 2 for comparison with other homologues. Further lengthening of the spacer from 6 atoms for compounds D6-12 to 12 carbon atoms D12-12 led to disappearance of mesophases (for details see ESI †).

The electro-optical behaviour of the $\mathrm{SmC}_{\mathrm{A}} \mathrm{P}_{\mathrm{A}}$ phase of all Dm12 compounds was found analogous to that described above for compounds D4-10 and D4-12. We have evaluated the layer spacing values by X-ray measurements. For compound D5-12 the results are presented in ESI in Fig. S3, $\uparrow$ where the intensity versus the scattering angle at $T=35{ }^{\circ} \mathrm{C}$ and the temperature dependence of the layer spacing, $d$, are shown. The layer spacing for D5-12 (34.5-35 ̊) is only slightly smaller than $d$ value found for D4-12 (Fig. 7). This can be connected with differences in tilt angle and/or modification of the overall dimer shape. Very small decrease of the layer spacing value on cooling for D4-12 can be explained with a slight increase of the molecular tilt in the $\mathrm{SmC}_{\mathrm{A}} \mathrm{P}_{\mathrm{A}}$ phase.

\section{Modification of the terminal chains}

Furthermore we changed the polar character of the terminal chain by introduction polyfluoroalkyl $(9,9,10,10,11,11,12,12,12-$ nonafluorododecyl) and siloxanylalkyl (11-(1,1,3,3,3)-pentamethyldisiloxanyl)undecyl chains to design materials Dm-1212FF, Dm-FF-FF, D3-12F-12F, D3-11F-11F，D3-SiF-SiF (Table 3). The motivation was to modify the self-assembly process and polar packing of the investigated dimers. ${ }^{30-34}$ At first, a series of materials Dm-1212-FF ( $m=2-5)$ was prepared, in which the upper bent-unit possesses the dodecyl terminal chains

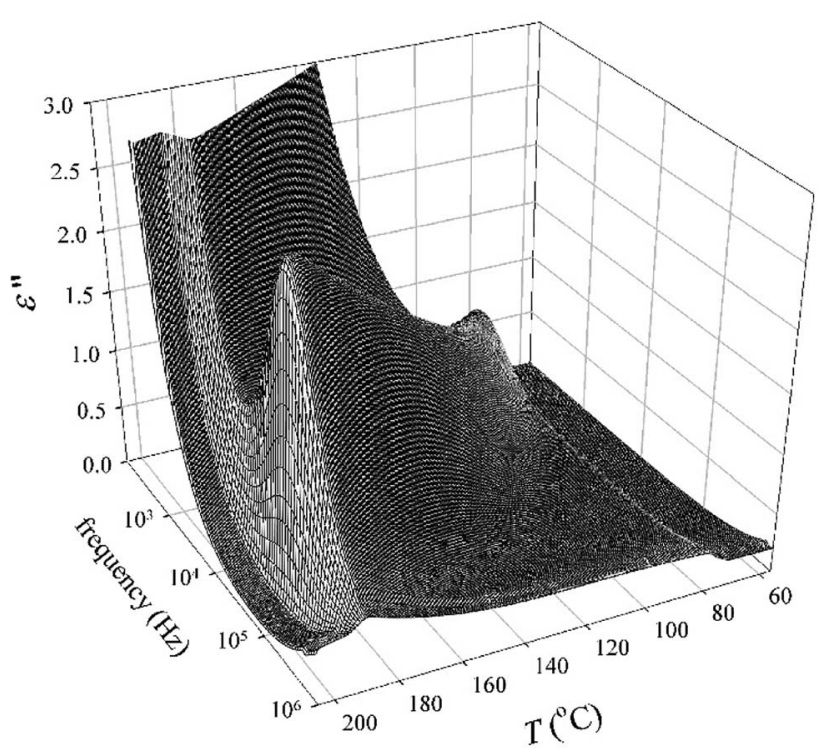

Fig. 9 Three-dimensional plot of the imaginary part of dielectric permittivity, $\varepsilon^{\prime \prime}$, versus temperature, $T$, and frequency in the $\mathrm{SmC}_{A} \mathrm{P}_{\mathrm{A}}$ phase for D3-FF-FF. 


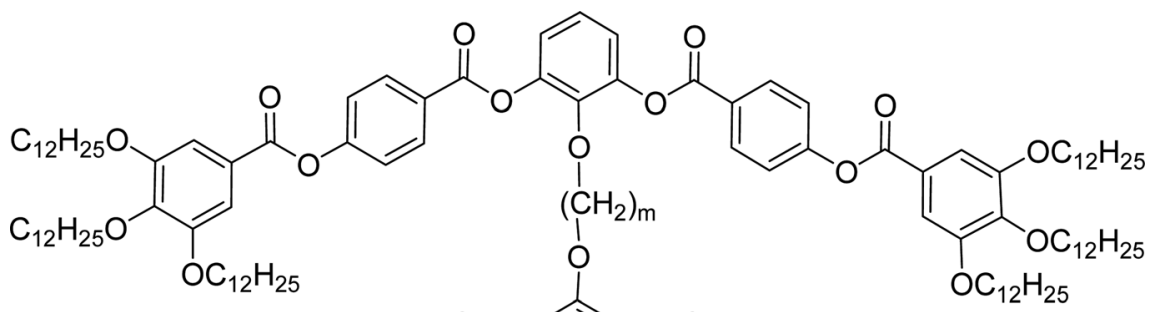

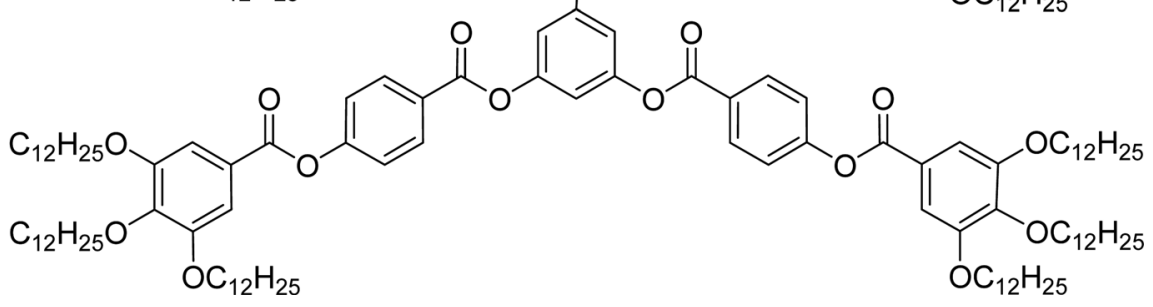

\begin{tabular}{|c|c|c|c|c|c|c|}
\hline Comp. & $m$ & $\mathrm{mp}[\Delta H]$ & $T_{\mathrm{cr}}[\Delta H]$ & $\mathrm{M}_{1}$ & $T_{\mathrm{tr}}[\Delta H]$ & Iso \\
\hline D3-12/3 & 3 & $-30[+36.4]$ & $-7[-37.4]$ & $\mathrm{Col}_{\mathrm{h}}$ & $45[-4.4]$ & • \\
\hline D4-12/3 & 4 & $-30[+31.5]$ & $-8[-40.5]$ & $\mathrm{Col}_{\mathrm{h}}$ & $43[-3.9]$ & • \\
\hline
\end{tabular}

${ }^{a}$ Melting point, mp, phase transition temperatures, $T_{\mathrm{tr}}$, and temperature of crystallization, $T_{\mathrm{cr}}$, in ${ }^{\circ} \mathrm{C}$, and corresponding enthalpy changes, $\Delta H$, in $\mathrm{kJ} \mathrm{mol}^{-1}$, detected on the second temperature run at a rate of $5 \mathrm{~K} \mathrm{~min}^{-1}$ are in brackets.

(symmetrically in both arms), while the bottom unit was terminated with a polyfluoroalkyl units. At the same time the distance between bent-core units was modified by changing the length of the alkylenedioxy spacer $(m=2-5)$. Compounds are formally symmetrical along the vertical axis. In spite of our strategy, such structural change did not exert a substantial influence on mesomorphic properties in comparison with materials Dm-12 (Table 2) and all materials exhibited the SmCP phase. The mesomorphic behaviour is summarized and compared in Table 3. Presence of two polyfluoroalkyl chains resulted in the increase of transition temperatures and the mesophase stability range. When all the dodecyl terminal chains were fully replaced by polyfluoroalkyl chains in compounds Dm-FF-FF $(m=3,4)$ further rise of clearing temperatures and stabilization of the SmCP phase is proved (Table 3) in comparison with compounds Dm-12.

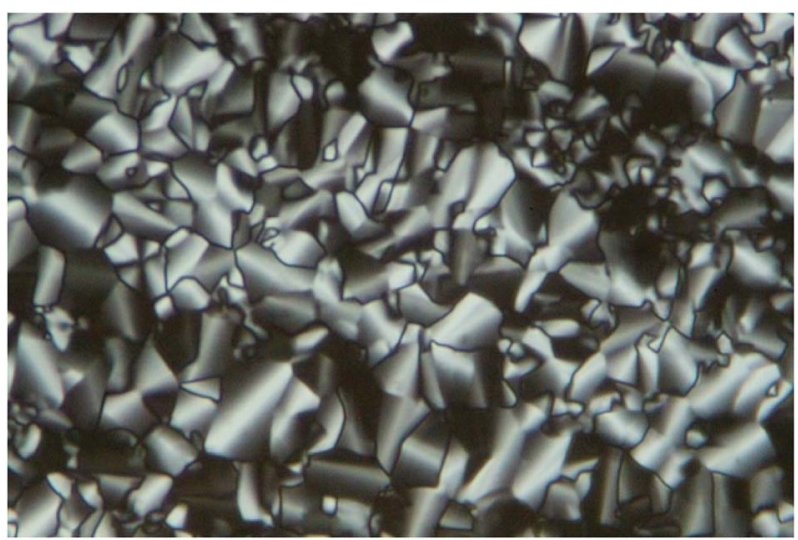

Fig. 10 Texture of $\mathrm{D} 3-12 / 3$ at $T=30{ }^{\circ} \mathrm{C}$. The width of the figure corresponds to $300 \mu \mathrm{m}$.
Other type of asymmetry was introduced into the dimers when both the upper and bottom units were terminated with different chains. We have utilized dodecyl/polyfluoroalkyl in D3-12F-12F, undecenyl/polyfluoroalkyl in D3-11F-11F, and pentamethyldisiloxane undecyl/polyfluoroalkyl chains in D3SiF-SiF. However, regardless the change in character of the terminal chains, the materials kept their phases and all prepared homologues exhibited broad $\mathrm{SmC}_{\mathrm{A}} \mathrm{P}_{\mathrm{A}}$ phases with small shifts in the phase transition temperatures only. Selected DSC thermographs are presented in ESI (Fig. S4) $\dagger$ for illustration. Compounds D4-1212-FF, D5-1212-FF and D3-FF-FF did not crystallise on cooling during DSC measurements but crystallised on subsequent heating run. It is visible as an opposite peak on the heating curve (Fig. S4a†).

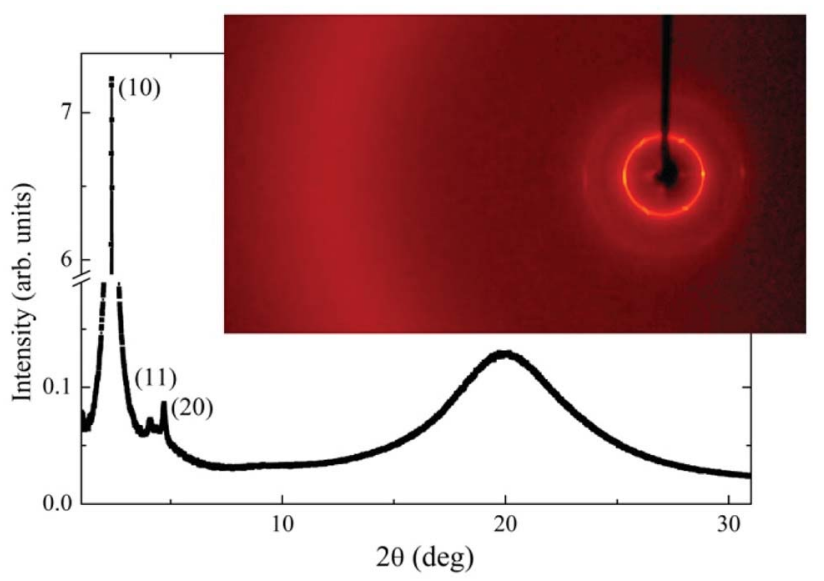

Fig. 11 Intensity of the $X$-ray signal versus scattering angle in a wide range for $\mathrm{D} 3-12 / 3$ at $T=25^{\circ} \mathrm{C}$ in the $\mathrm{Col}_{\mathrm{h}}$ phase. In the inset $2 \mathrm{D} X$-ray pattern is shown at the same temperature. 
Table 5 Mesomorphic properties of dimers with modified linking groups ${ }^{a}$

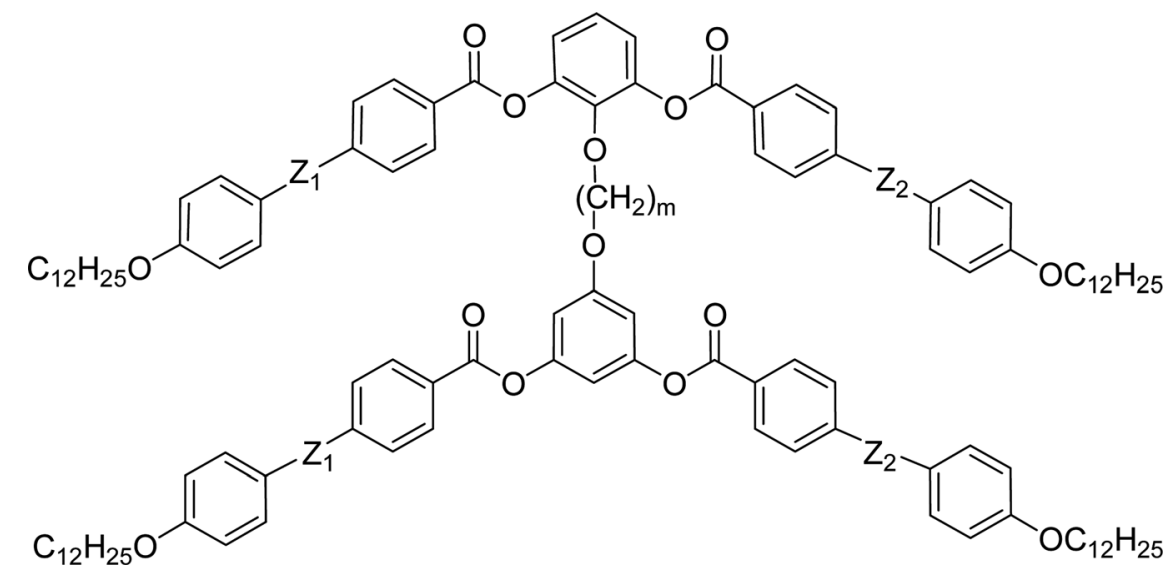

\begin{tabular}{|c|c|c|c|c|c|c|c|c|}
\hline Comp. & $m$ & $\mathrm{Z}_{1}$ & $\mathrm{Z}_{2}$ & $\mathrm{mp}[\Delta H]$ & $T_{\mathrm{cr}}[\Delta H]$ & $\mathrm{M}_{1}$ & $T_{\mathrm{tr}}[\Delta H]$ & Iso \\
\hline D3-12/inv & 3 & OOC & $\mathrm{COO}$ & $118[+40.2]$ & $100[-10.3]$ & $\mathrm{SmC}_{\mathrm{A}} \mathrm{P}_{\mathrm{A}}$ & $201[-31.0]$ & • \\
\hline D4-12/inv & 4 & OOC & $\mathrm{COO}$ & $119[+28.4]$ & $98[-24.7]$ & $\mathrm{SmC}_{\mathrm{A}} \mathrm{P}_{\mathrm{A}}$ & $190[-38.9]$ & - \\
\hline D4-12/azo & 4 & $\mathrm{~N}=\mathrm{N}$ & $\mathrm{N}=\mathrm{N}$ & $137[+60.5]$ & $101[-32.2]$ & $\mathrm{SmC}_{\mathrm{A}} \mathrm{P}_{\mathrm{A}}$ & $142[-24.5]$ & • \\
\hline D3-12/Ph2 & 3 & - & - & $150[+44.9]$ & $144[-22.0]$ & $\mathrm{SmC}_{\mathrm{A}} \mathrm{P}_{\mathrm{A}}$ & $149[-27.2]$ & • \\
\hline D4-12/Ph2 & 4 & - & - & $134[+36.8]$ & $107[-29.0]$ & $\mathrm{SmC}_{\mathrm{A}} \mathrm{P}_{\mathrm{A}}$ & $139[-34.9]$ & - \\
\hline
\end{tabular}

${ }^{a}$ Melting point, mp, phase transition temperatures, $T_{\mathrm{tr}}$, and temperature of crystallization, $T_{\mathrm{cr}}$, in ${ }^{\circ} \mathrm{C}$, and corresponding enthalpy changes, $\Delta H$, in $\mathrm{kJ} \mathrm{mol}^{-1}$, are in brackets.

All the compounds listed in Tables 2 and 3 exhibited the $\mathrm{SmC}_{\mathrm{A}} \mathrm{P}_{\mathrm{A}}$ mesophase with similar electro-optical behaviour, and can be described together. Textures and their behaviour in the applied electric field were described above for D4-10 and D4-12 (Fig. 4-6). The only difference concerns the threshold voltage, $E_{\mathrm{th}}$, at which the electro-optical changes can be observed. $E_{\mathrm{th}}$, for fluorinated compounds Dm-1212-FF and Dm-FF-FF is about $10 \mathrm{~V} \mu \mathrm{m}^{-1}$, which is lower in comparison with $E_{\text {th }} \approx 15 \mathrm{~V} \mathrm{\mu m}^{-1}$ for D4-10 and D4-12. Very small threshold voltage, $E_{\mathrm{th}} \approx 2 \mathrm{~V}$ $\mu \mathrm{m}^{-1}$, was found for compound with oligosiloxane units in the terminal chain, D3-SiF-SiF. Switching current for D3-SiF-SiF reveals only on distinct peak per half period of applied voltage, as it is shown in Fig. 8, which results from overlap of the signals coming from two consecutive switching events. Polarization values have been evaluated $800-1000 \mathrm{nC} \mathrm{cm}^{-2}$ for compounds from Table 3. Dielectric spectroscopy performed for D3-SiF-SiF (see Fig. S5†) and D3-FF-FF (Fig. 9) showed that the dielectric behaviour exhibits very similar features to other presented compounds with the $\mathrm{SmC}_{\mathrm{A}} \mathrm{P}_{\mathrm{A}}$ phase (see Fig. $\mathrm{S} 2 \dagger$ for D4-10). It evidences of the similar type of structures and arrangement of molecules in all observed tilted lamellar mesophases.

The X-ray measurements were performed for all compounds from Table 3 and the tilted lamellar mesophase presence was confirmed. Due to analogy with compounds studied above (see Fig. 7), the results are summarized in ESI. $\dagger$ In Fig. S6 $\dagger$ the X-ray measurements is demonstrated for compound D4-1212-FF, which exhibits the layer spacing, $d$, decreasing on cooling from $38.8 \AA$ to $36.9 \AA$ A. In Fig. S7, $\dagger$ the X-ray intensity versus scattering angle is presented in $2 \mathrm{D}$ picture for $\mathrm{D} 3-\mathbf{1 1 F}-11 \mathrm{~F}$ at $T=100^{\circ} \mathrm{C}$ and layer spacing was established $38.7 \AA$. Similar temperature behaviour and layer spacing values have been detected for other compounds. Only for compound D3-SiF-SiF, $d(T)$ values slightly increases on cooling and reaches higher values than other compounds $(d \approx 42 \AA)$. Temperature dependence $d(T)$ for D3-SiFSiF is presented in ESI (Fig. S8). $\dagger$ The length of the molecule for D3-SiF-SiF has been calculated and found to be about $56.5 \AA$, which corresponds to the tilt angle $42 \mathrm{deg}$.

\section{Modification of the number of terminal chains}

Additionally, we have made an attempt to increase the size and/ or modify the shape of the dimer by joining three alkyl chains to the terminal rings to mimic a polycatenar system. The dimers D3-12/3 and D4-12/3 (Table 4) decorated with dodecyl alkyl chains exhibited interesting mesomorphism. The compounds are low-melting and show a hexagonal columnar phase. Planar texture is presented in Fig. 10 for a non-aligned cell without surfactant. The sample is sensitive to shearing and textures can be aligned in this way (see Fig. S9 in ESI $\dagger$ ).

$\mathrm{X}$-ray measurements have been performed to confirm the phase identification and establish the structural parameters of the columnar phase. Presence of three sharp low-angle signals, which positions in q-space are in sequence 1:sqrt(3):2 (Fig. 11) confirms the hexagonal arrangement of columns. For both compounds, D3$12 / 3$ and D4-12/3, the lattice parameter, $a$, which is a measure of column diameter, was found comparable (Table S2 in ESI $\dagger$ ).

\section{Modification of the polar linkages}

A typical modification of the bent-core liquid crystal structure involves change of the polar linkages within the molecular 
arms. ${ }^{1}$ In this respect, for materials with propylenedioxy and butylenedioxy spacers with uniform dodecyl terminal chains we reoriented the ester linkages in the outer positions of arms in materials Dm-12/inv. Further, we have substituted the ester linkage for azo moieties in Dm-12/azo. Finally, we have also removed the ester groups completely to form rigid biphenyl units in the arms for Dm-12/Ph2 (Table 5).

Reorientation of ester groups in the ester based materials Dm-12/inv $\left(\mathrm{Z}_{1}=\mathrm{COO}, \mathrm{Z}_{2}=\mathrm{OOC}\right)$ does not disturb formation of the $\mathrm{SmC}_{\mathrm{A}} \mathrm{P}_{\mathrm{A}}$, moreover the increase of the Iso-SmCP transition

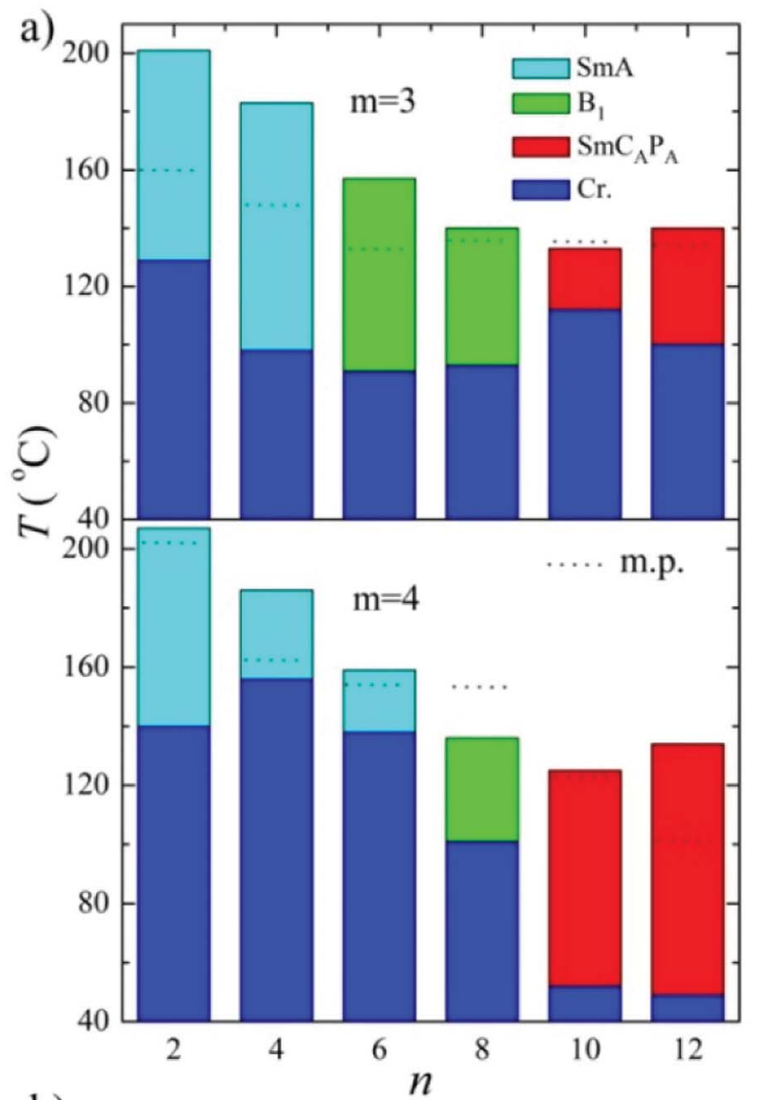

b)

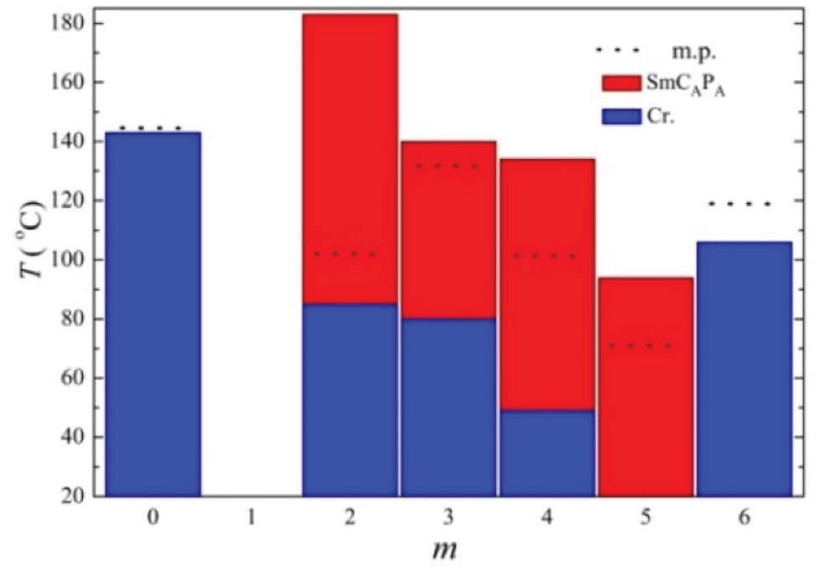

Fig. 12 Effect of spacer length $(m)$ on mesomorphic properties: (a) phase transition temperatures and phases versus terminal chain length (n) for $m=3$ and $m=4$, (b) versus the spacer length $(m)$ for compounds Dm-12. temperatures for more than $45 \mathrm{~K}$ with respect to parent compounds D3-12 and D4-12, has been observed. Replacement for a more rigid azo linking groups (Dm-12/azo, $\mathrm{Z}_{1}=\mathrm{Z}_{2}=\mathrm{N}=\mathrm{N}$ ) also preserved the mesomorphic behaviour and formation of the $\mathrm{SmC}_{\mathrm{A}} \mathrm{P}_{\mathrm{A}}$ phases was observed, however in narrower temperature intervals. Finally, the same mesomorphic behaviour was observed also for materials with biphenyl units in the side arms (Dm-12/Ph2), where still narrower $\mathrm{SmC}_{\mathrm{A}} \mathrm{P}_{\mathrm{A}}$ phases were found. The DSC thermographs for selected compounds from this series are presented in ESI (Fig. S10). $\uparrow$ The performed $\mathrm{X}$-ray measurements confirmed the lamellar character of mesophase in all modified compounds. Additionally, we have studied electro-optical properties to establish polar character of the $\mathrm{SmC}_{\mathrm{A}} \mathrm{P}_{\mathrm{A}}$ phase. We can conclude that the character and electro-optical response of the $\mathrm{SmC}_{\mathrm{A}} \mathrm{P}_{\mathrm{A}}$ phase remains unchanged. Dielectric spectroscopy data evidencing polar mode is presented in ESI (Fig. S11 for D4-12/inv). $\dagger$ Imaginary part of permittivity, $\varepsilon^{\prime \prime}$, shows distinct maxima at a frequency of about $10 \mathrm{kHz}$. Switching current with characteristic profile with two peaks in half-cycle is presented in ESI for D4-12/Ph2 (Fig. S12) $\bullet \dagger$ Polarization values have been calculated $P_{\mathrm{S}} \approx 700-900 \mathrm{nC} \mathrm{cm}^{-2}$ for compounds listed in Table 5 . In conclusion, increasing the rigidity of the lengthening arms resulted in narrowing the interval of SmCP phases.

\section{Discussion and conclusions}

To summarize, we have found that the character of mesophase exhibited by top-to-bottom bent-core dimers strongly depends on the length of terminal chains. The shortest homologues exhibit the SmA phase, for the average terminal chain length a columnar $\mathrm{B}_{1}$ phase is formed and while the longest homologues reveal switchable lamellar mesophases. The butylenedioxy homologues D4-n exhibited the intercalated SmA phase for $n=2,4$ and 6. We should stress that all observed SmA phases reveal similar character: SmA is non-polar orthogonal phase with the layer spacing value close to half-length of the molecule, which evidences deep intercalation for this type of phase. Such a phase is non-switchable and does not respond to applied electric field. For propylenedioxy derivative D3-6 the columnar $\mathrm{B}_{1}$ phase was reported, on contrary, D4-6 shows the SmA phase. In the columnar $\mathrm{B}_{1}$ phase with a structure of "broken-layers" the dimeric molecules are more organized that in the SmA phase. One can conclude the lengthening of the spacer for $n=6$ disturbs packing of molecules and a less ordered phase is preferred.

The effect of the terminal chain length ( $n$ number) for series D3-n and D4-n is presented in Fig. 12a. For long terminal chains, $n=10$ and 12, we have observed the switchable $\operatorname{SmC}_{\mathrm{A}} \mathrm{P}_{\mathrm{A}}$ phase, characteristic for bent-core monomeric mesogens. For all studied mesogens with $\mathrm{SmC}_{\mathrm{A}} \mathrm{P}_{\mathrm{A}}$ phase the physical properties are similar and can be described together. The ground state is anticlinic, as is clearly demonstrated in planar textures by optical extinction oriented along the smectic layer normal (along the fan symmetry-axis). Under applied electric filed the extinction position rotates and reveals inclination from the ground position, which corresponds to transformation into 
synclinic state under the field. Such behaviour is characteristic for $\mathrm{SmC}_{\mathrm{A}} \mathrm{P}_{\mathrm{A}}-\mathrm{SmC}_{\mathrm{S}} \mathrm{P}_{\mathrm{F}}$ transformation in the electric field for bent-core compounds. ${ }^{2}$ From this type of electro-optical behaviour we can imagine the dimer response to the electric field in a similar manner as is described for bent-core molecules.

For terminal chain $n=12$ we have found that up to the spacer length $m=5$ we can observe mesogenic properties, the above described $\operatorname{SmC}_{\mathrm{A}} \mathrm{P}_{\mathrm{A}}$ phase. For compounds with $m \geq 6$ mesomorphic properties are lost, which is obviously caused by larger mutual independence of the single bent units and change of supramolecular packing. In Fig. $12 \mathrm{~b}$ it is demonstrated the shift of the temperature interval of the $\operatorname{SmC}_{\mathrm{A}} \mathrm{P}_{\mathrm{A}}$ phase to lower temperatures with increasing $m$ value. We found that there is no typical odd/even effect of the spacer parity on the mesomorphic properties for studied type of dimers.

One of the important requirements for the formation of bent-core phases is the microsegregation of the rigid polar bentcore structure from the terminal and less polar alkyl groups. ${ }^{1}$ The extent of microsegregation can be modified by introduction of different chains, e.g., polyfluoroalkyl and oligosiloxane units, which are incompatible with alkyl and aromatic units, respectively. Generally, for simple bent-core molecules the presence of the fluorinated chains ${ }^{31-33}$ causes the broadening and stabilization of lamellar phases and increase of clearing temperatures. To modify the mesogenic properties of switchable SmCP phases for the present study of top-to-bottom dimers, we concentrated on long terminal chains and varied their structure. Fluorination of terminal chains did not substantially affect the mesophase character. Nevertheless, compound D3-SiF-SiF with the siloxanylalkyl chains exhibited a very low threshold voltage for the electro-optical switching from antiferro to ferroelectric state. We can summarize that by variation of the terminal chains we have stabilized the $\operatorname{SmC}_{\mathrm{A}} \mathrm{P}_{\mathrm{A}}$ mesophases and optimized their electro-optical properties.

Rather unique attempt to modify the structures of dimers by substituting of multiple terminal chains to outer phenyl rings led to a polycatenar system that exhibited substantially decreased transition temperatures and different type of liquid crystalline phases - instead of lamellar phases a columnar hexagonal phase was found.

\section{Conflicts of interest}

The authors declare no conflict of interest.

\section{Acknowledgements}

This work was supported by the Czech Science Foundation (project 18-14497S).

\section{References}

1 N. Gimeno and M. B. Ros, Chemical structures, mesogenic properties, and synthesis of liquid crystals with bent-core structure, in: Handbook of Liquid Crystals, ed. J. W. Goodby, P. J. Collings, T. Kato, C. Tschierske, H. F. Gleeson, P.
Raynes, Wiley-VCH, Weinheim, 2014, 4, p. 603, and references cited therein.

2 H. Takezoe, Top. Curr. Chem., 2012, 318, 303-330.

3 A. Eremin and A. Jakli, Soft Matter, 2013, 9, 615-637.

4 M. Alaasar, M. Prehm, S. Poppe and C. Tschierske, Chem.Eur. J., 2017, 23, 5541-5556.

5 J. Szydlowska, J. Mieczkowski, J. Matraszek, D. W. Bruce, E. Gorecka, D. Pociecha and D. Guillon, Phys. Rev. E: Stat., Nonlinear, Soft Matter Phys., 2003, 67, 031702.

6 J. Verara, J. Barbera, J. L. Serrano, M. B. Ros, N. Sebastian, R. de la Fuente, D. O. Lopez, G. Fernandez, L. Sanchez and N. Martin, Angew. Chem., Int. Ed., 2011, 50, 12523.

7 S. Pan, B. Mu, Y. Zhou, Q. Li, B. Wu, J. Fang and D. Chen, RSC Adv., 2016, 6, 49556.

8 G. Dantlgraber, S. Diele and C. Tschierske, Chem. Commun., 2002, 2768.

9 C. Keith, R. Amaranatha Reddy, U. Baumeister, H. Hahn, H. Lang and C. Tschierske, J. Mater. Chem., 2006, 16, 3444.

10 R. Achten, A. Koudijs, M. Giesbers, A. T. M. Marcelis, E. J. R. Sudhölter, M. W. Schroeder and W. Weissflog, Liq. Cryst., 2007, 34, 59.

11 B. Kosata, G. M. Tamba, U. Baumeister, K. Pelz, S. Diele, G. Pelzl, G. Galli, S. Samaritani, E. V. Agina, N. I. Boiko, V. P. Shibaev and W. Weissflog, Chem. Mater., 2006, 18, 691.

12 S. Radhika, B. K. Sadashiva and V. A. Raghunathan, Liq. Cryst., 2013, 40, 1209.

13 G. Shanker, M. Prehm and C. Tschierske, J. Mater. Chem., 2012, 22, 168.

14 L.-Y. Zhang, Q.-K. Zhang and Y.-D. Zhang, Liq. Cryst., 2013, 40, 1263.

15 S. Umadevi and B. K. Sadashiva, Liq. Cryst., 2007, 34, 673.

16 S. Umadevi, B. K. Sadashiva, H. N. Shreenivasa Murthy and V. A. Raghunathan, Soft Matter, 2006, 2, 210.

17 N. Sebastián, N. Gimeno, J. Vergara, D. O. López, J. L. Serrano, C. L. Folcia, M. R. de la Fuente and M. B. Ros, J. Mater. Chem. C, 2014, 2, 4027.

18 C. M. Hegguilustoy, M. B. Darda, R. S. Montani, B. Heinrich, B. Donnio, D. Guillon and R. O. Garay, Liq. Cryst., 2015, 42, 1013.

19 Y. Wang, H. G. Yoon, H. K. Bisoyi, S. Kumar and Q. Li, J. Mater. Chem., 2012, 22, 20363.

20 C. V. Yelamaggad, S. K. Prasad, G. G. Nair, I. S. Shashikala, D. S. S. Rao, C. V. Lobo and S. Chandrasekhar, Angew. Chem., Int. Ed., 2004, 43, 3429.

21 N. G. Nagaveni, V. Prasad and A. Roy, Liq. Cryst., 2013, 40, 1001.

22 M.-G. Tamba, B. Kosata, K. Pelz, S. Diele, G. Pelzl, Z. Vakhovskaya, H. Kresse and W. Weissflog, Soft Matter, 2006, 2, 60.

23 C. V. Yelamaggad, I. S. Shashikala, G. Liao, D. S. Shankar Rao, S. K. Prasad, Q. Li and A. Jakli, Chem. Mater., 2006, 18, 6100.

24 M.-G. Tamba, U. Baumeister, G. Pelzl and W. Weissflog, Liq. Cryst., 2010, 37, 853.

25 C. V. Yelamaggad, S. A. Nagamani, S. A. Hiremath and G. G. Nair, Liq. Cryst., 2001, 28, 1009. 
26 S. K. Prasad, G. G. Nair, D. S. S. Rao, C. V. Lobbo, I. S. Shashikala and C. V. Yelamaggad, Mol. Cryst. Liq. Cryst., 2005, 437, 211.

27 M. Horčic, J. Svoboda, A. Seidler, V. Kozmík, V. Novotná, D. Pociecha and E. Gorecka, RSC Adv., 2016, 6, 41972.

28 M. Horčic, J. Svoboda, V. Novotná, D. Pociecha and E. Gorecka, Chem. Commun., 2017, 53, 2721.

29 L. Guo, K. Gomola, E. Gorecka, D. Pociecha, S. Dhara, F. Araoka, K. Ishikawa and H. Takezoe, Soft Matter, 2011, 7, 2895.
30 V. Novotná, M. Kašpar, V. Hamplová, M. Glogarová, L. Lejček, J. Kroupa and D. Pociecha, J. Mater. Chem., 2006, 16, 2031.

31 D. Shen, A. Pegenau, S. Diele, I. Wirth and C. Tschierske, J. Am. Chem. Soc., 2000, 122, 1593.

32 L. Kovalenko, W. Weissflog, S. Grande, G. Pelzl and I. Wirth, Liq. Cryst., 2000, 27, 683.

33 A. Kovářová, V. Kozmík, J. Svoboda, V. Novotná, M. Glogarová and D. Pociecha, Liq. Cryst., 2012, 39, 755.

34 G. Dantlgraber, A. Eremin, S. Diele, A. Hauser, H. Kresse, G. Pelzl and C. Tschierske, Angew. Chem., Int. Ed., 2002, 41, 2408. 